\title{
A Nonlinear Autoregressive Distributed Lag (NARDL) Analysis on the Determinants of Vietnam's Stock Market
}

\author{
Le Hoang Phong, ${ }^{1,2}$, Dang Thi Bach Van'1, Ho Hoang Gia Bao² \\ ${ }^{1}$ School of Public Finance, University of Economics Ho Chi Minh City, 59C Nguyen Dinh Chieu, District 3, Ho \\ Chi Minh City, Vietnam. \\ ${ }^{2}$ Department of Finance and Accounting Management, Faculty of Management, Ho Chi Minh City University \\ of Law, 02 Nguyen Tat Thanh, District 4, Ho Chi Minh City, Vietnam. \\ E-mail: hphong@hcmulaw.edu.vn, bachvan@ueh.edu.vn, hhgbao@hcmulaw.edu.vn
}

\begin{abstract}
This study examines the impacts of some macroeconomic factors, including exchange rate, interest rate, money supply and inflation, on a major stock index of Vietnam (VNIndex) by utilizing monthly data from April, 2001 to October, 2017 and employing Non-linear Autoregressive Distributed Lag (NARDL) approach introduced by Shin et al. [33] to investigate the asymmetric effects of the aforementioned variables. The bound test verifies asymmetric cointegration among the variables, thus the long-run asymmetric influences of the aforesaid macroeconomic factors on VNIndex can be estimated. Besides, we apply Error Correction Model (ECM) based on NARDL to evaluate the short-run asymmetric effects. The findings indicate that money supply improves VNIndex in both short-run and long-run, but the magnitude of the negative cumulative sum of changes is higher than the positive one. Moreover, the positive (negative) cumulative sum of changes of interest rate has negative (positive) impact on VNIndex in both short-run and long-run, but the former's magnitude exceeds the latter's. Furthermore, exchange rate demonstrates insignificant effects on VNIndex. Also, inflation hampers VNIndex almost linearly. This result provides essential implications for policy makers in Vietnam in order to successfully manage and sustainably develop the stock market.
\end{abstract}

Keywords: macroeconomic factors, stock market, nonlinear ARDL, Asymmetric Bound test

\section{Introduction}

Vietnam's stock market was established on 20 July, 2000 when Ho Chi Minh City Securities Trading Center (HOSTC) was officially opened. For nearly two decades, Vietnam's stock market has grown significantly when the current market capitalization occupies 70\% GDP, compared to $0.28 \%$ in the year 2000 with only 2 listed companies.

It is obvious that the growth of stock market has become an important source of capital and played an essential role in contributing to the sustainable economic development. Accordingly, policy makers must pay attention to the stable development of stock market, and one crucial aspect to be considered is the examination of the stock market's determinants, especially macroeconomic factors.

We conduct this consequential study to evaluate the impacts of macroeconomic factors on a major stock index of Vietnam (VNIndex) by NARDL approach. The main content of this study complies with a standard structure in which literature review is presented first, followed by estimation methodology and empirical results. Crucial tests and analyses including unit root test, bound test, NARDL model specification, diagnostic tests and estimations of short-run and long-run impacts are also demonstrated. 


\section{Literature Review}

Stock index represents the prices of virtually all stocks on the market. As stock price of each company is affected by economic circumstances, stock index is also impacted by micro- and macroeconomic factors.

There are many theories that can explain the relationship between stock index and macroeconomic factors, and among them, Arbitrage Pricing Theory (APT) has been extensively used in studies scrutinizing the relationship between stock market and macroeconomic factors.

Nonetheless, the APT model has a drawback as it assumes the constant term to be a risk-free rate of return [3]. Other models, however, presume the stock price as the current value of all expected future dividends [5], and it is calculated as follows:

$$
P_{t}=\sum_{i=1}^{\infty} \frac{1}{(1+\rho)^{i}} \cdot E\left(d_{t+i} \mid h_{t}\right)
$$

where $P_{t}$ is the stock price at time $\mathrm{t} ; \rho$ is the discount rate; $d_{t}$ is the dividend at time $\mathrm{t} ; h_{t}$ is the collection of all available information at time t. Equation (1) consists of 3 main elements: the growth of stock in the future, the risk-free discount rate and the risk premium contained in $\rho$; see, e.g., [2].

Stock price reacts in the opposite direction with a change in interest rate. An increase in interest rate implies that investors have higher profit expectation, and thus, the discount rate accrues and stock price declines. Besides, the relationship between interest rate and investment in production can be considerable because high interest rate discourages investment, which in turn lowers stock price. Consequently, interest rate can influence stock price directly through discount rate and indirectly through investment in production. Both the aforementioned direct and indirect impacts make stock price negatively correlate with interest rate.

Regarding the impact of inflation, stock market is less attractive to investors when inflation increases because their incomes deteriorate due to the decreasing value of money. Meanwhile, higher interest rate (in order to deal with inflation) brings higher costs to investors who use leverage or limits capital flow into the stock market or diverts the capital to other safer or more profitable investment types. Furthermore, the fact that revenues of companies are worsened by inflation, together with escalating costs (capital costs, input costs resulting from demand-pull inflation), aggravates the expected profits, which negatively affects their stock prices. Hence, inflation has unfavorable impact on stock market.

Among macroeconomic factors, money supply is often viewed as an encouragement for the growth of stock market. With expansionary monetary policy, interest rate is lowered, companies and investors can easily access capital, which fosters stock market. In contrast, with contractionary monetary policy, stock market is hindered.

Export and import play an important role in many economies including Vietnam, and exchange rate is of the essence. When exchange rate increases (local currency depreciates against foreign currency), domestically produced goods become cheaper, and thus, export is enhanced and exporting companies' performances are improved while the import side faces difficulty, which in turn influences stock market. Also, incremental exchange rate attracts capital flow from foreign investors into stock market. The effect of exchange rate, nevertheless, can vary and be subject to specific situations of listed companies on the stock market as well as the economy.

Empirical researches find that stock index is influenced by macroeconomic factors such as interest rate, inflation, money supply, exchange rate, oil price, industrial output, etc. Concerning the link between interest rate and stock index, many studies conclude the negative relationship. Rapach et al. [29] show that interest rate is one of the consistent and reliable predictive elements for stock profits in some European countries. Humpe and Macmillan [12] observe negative impact of long-term interest rate on American stock market. Peiró [21] detects negative impact of interest rate and positive impact of industrial output on stock markets in France, Germany and UK, which is similar to the subsequent 
repetitive study of Peiró [22] in the same countries. Jareño and Navarro [14] confirm the negative association between interest rate and stock index in Spain. Wongbangpo and Sharma [32] find negative connection between inflation and stock indices of 5 ASEAN countries (Indonesia, Malaysia, Philippines, Singapore and Thailand); in the meantime, interest rate has negative linkage with stock indices of Singapore, Thailand and Philippines.

Hsing [11] indicates that budget deficit, interest rate, inflation and exchange rate have negative relationship with stock index in Bulgaria over the 2000-2010 period. Naik [18] employs VECM model on quarterly data from 1994Q4 to 2011Q4, finds that money supply and industrial production index improve the stock index of India, while inflation exacerbates it, and the roles of interest rate and exchange rate are statistically insignificant. Vejzagic and Zarafat [31] conclude that money supply fosters the stock market of Malaysia, while inflation and exchange rate hamper it. Gul and Khan [9] explores that exchange rate has positive impact on KSE 100 (the stock index of Pakistan) while that of money supply is negative. Ibrahim and Musah [13] examine Ghana's stock market from October 2000 to October 2010 by using VECM model and denote enhancing causation of inflation and money supply, while interest rate, exchange rate and industrial production index bring discouraging causality. Mutuku and Ng'eny [17] use VAR method on quarterly data from 1997Q1 to 2010Q4 and find that inflation has negative effect on Kenya's stock market while other factors such as GDP, exchange rate and bond interest have positive impacts. In Vietnam, Nguyet and Thao [19] explored that money supply, inflation, industrial output and world oil price can facilitate stock market while interest rate and exchange rate hinder it during July 2000 and September 2011.

From the above literature review, we include 4 factors (inflation, interest rate, money supply and exchange rate) in the model to explain the change of VNIndex.

\section{Estimation Methodology}

\subsection{Unit Root Test}

Stationarity is of the essence in scrutinizing time series data. A time series is stationary if its mean and variance do not change over time. Stationarity can be tested by several methods: ADF

(Augmented Dickey-Fuller) [7], Phillips-Perron [26], and KPSS [16]. In several papers, the ADF test is often exploited in unit root test.

The simplest case of unit root testing considers an $\mathrm{AR}(1)$ process:

$$
Y_{t}=m \cdot Y_{t-1}+\varepsilon_{t}
$$

where $Y_{t}$ denotes the time series; $Y_{t-1}$ indicates the one-period-lagged value of $Y_{t} ; m$ is the coefficient; and $\varepsilon_{t}$ is the error term. If $m<1$, the series is stationary (i.e. no unit root). If $m=1$, the series is nonstationary (i.e. unit root exists) The aforesaid verification for unit root is normally known as DickeyFuller test, which can be alternatively expressed as follows by subtracting $Y_{t-1}$ in each side of the AR(1) process:

$$
\Delta Y_{t}=(m-1) \cdot Y_{t-1}+\varepsilon_{t}
$$

Let $\gamma=m-1$, the model then becomes:

$$
\Delta Y_{t}=\gamma \cdot Y_{t-1}+\varepsilon_{t}
$$

Now, the conditions for stationarity and non-stationarity are respectively $\gamma<0$ and $\gamma=0$.

Nonetheless, the Dickey-Fuller test is only valid in case of AR(1) process. If $A R(p)$ process is 
necessitated, the Augmented Dickey-Fuller (ADF) test must be employed because it permits $p$ lagged values of $Y_{t}$ as well as the inclusion of a constant and a linear time trend, which is written as follows:

$$
\Delta Y_{t}=\alpha+\beta \cdot t+\gamma \cdot Y_{t-1}+\sum_{j=1}^{p}\left(\phi_{j} \cdot \Delta Y_{t-j}\right)+\varepsilon_{t}
$$

In Eq. (5), $\alpha, \beta$, and $p$ are respectively the constant number, linear time trend coefficient and autoregressive order of lag. When $\alpha=0$ and $\beta=0$, the series is a random walk without drift, and in case only $\beta=0$, the series is a random walk. The null hypothesis of ADF test states that $Y_{t}$ has unit root and there is no stationarity. The alternative hypothesis states that $Y_{t}$ has no unit root and the series is stationary. In order to test for unit root. ADF test statistic is compared with a corresponding critical value: if the absolute value of the test statistic is smaller than that of the critical value, the null hypothesis cannot be rejected. In case the series is non-stationary, its difference is used. If the time series is stationary at level, it is called I(0). If the time series is non-stationary at level but the stationarity is achieved at the first difference, it is called I(1).

\subsection{Cointegration and NARDL Model}

Variables are deemed to be cointegrated if there exists a stationary linear combination or long-term relationship among them. For testing cointegration, traditional methods such as Engle-Granger [8] or Johansen [15] are frequently employed.

Nevertheless, when variables are integrated at $\mathrm{I}(0)$ or I(1), the 2-period-residual-based EngleGranger and the maximum-likelihood-based Johansen methods may produce biased results regarding long-run interactions among variables [8,15]. Relating to this issue, Autoregressive Distributed Lag (ARDL) method proposed by Pesaran and Shin [24] give unbiased estimations regardless of whether $\mathrm{I}(0)$ and $\mathrm{I}(1)$ variables exist in the model.

ARDL model in analyzing time series data has 2 components: "DL" (Distributed Lag)independent variables with lags can affect dependent variable and "AR" (Autoregressive)-lagged values of the dependent variable can also impact its current value. Going into detail, the simple case ARDL(1,1) is displayed as:

$$
Y_{t}=\alpha_{0}+\alpha_{1} \cdot Y_{t-1}+\beta_{0} \cdot X_{t}+\beta_{1} \cdot X_{t-1}+\varepsilon_{t}
$$

ARDL $(1,1)$ model shows that both independent and dependent variables have the lag order of 1 . In such case, the regression coefficient of $\mathrm{X}$ in the long-run equation is as follows:

$$
k=\frac{\beta_{0}+\beta_{1}}{1-\alpha_{1}} .
$$

ECM model based on ARDL(1,1) can be shown as:

$$
\Delta Y_{t}=\alpha_{0}+\left(\alpha_{1}-1\right) \cdot\left(Y_{t-1}-k \cdot X_{t-1}\right)+\beta_{0} \cdot \Delta X_{t-1}+\varepsilon_{t}
$$

The general ARDL model for one dependent variable $Y$ and a set of independent variables $X_{1}, X_{2}, X_{3}, \ldots, X_{n}$ is denoted as $\operatorname{ARDL}\left(p_{0}, p_{1}, p_{2}, p_{3} \ldots, p_{n}\right)$, in which $p_{0}$ is the lag order of $Y$ and the rest are respectively the lag orders of $X_{1}, X_{2}, X_{3}, \ldots, X_{n}$. ARDL $\left(p_{0}, p_{1}, p_{2}, p_{3} \ldots, p_{n}\right)$, is written as follows:

$$
\begin{aligned}
& Y_{t}=\alpha+\sum_{i=1}^{p_{0}}\left(\beta_{0, i} \cdot Y_{t-i}\right)+\sum_{j=0}^{p_{1}}\left(\beta_{1, j} \cdot X_{1, t-j}\right)+\sum_{k=0}^{p_{2}}\left(\beta_{2, k} \cdot X_{2, t-k}\right)+\sum_{l=0}^{p_{3}}\left(\beta_{3, t} \cdot X_{3, t-l}\right)+\ldots+ \\
& \sum_{m=0}^{p_{n}}\left(\beta_{n, m} \cdot X_{n, t-m}\right)+\varepsilon_{t} .
\end{aligned}
$$


ARDL methods begins with bound test procedure to identify the cointegration among the variables in other words the long-run relationship among the variables [23]. The Unrestricted Error Correction Model (UECM) form of ARDL is shown as:

$$
\begin{aligned}
& \Delta Y_{t}=\alpha+\sum_{i=1}^{p_{0}}\left(\beta_{0, i} \cdot \Delta Y_{t-i}\right)+\sum_{j=0}^{p_{1}}\left(\beta_{1, j} \cdot \Delta X_{1, t-j}\right)+\sum_{k=0}^{p_{2}}\left(\beta_{2, k} \cdot \Delta X_{2, t-k}\right)+\sum_{l=0}^{p_{3}}\left(\beta_{3, t} \cdot \Delta X_{3, t-l}\right)+\ldots+ \\
& \sum_{m=0}^{p_{n}}\left(\beta_{n, m} \cdot \Delta X_{n, t-m}\right)+\lambda_{0} \cdot Y_{t-1}+\lambda_{1} \cdot X_{1, t-1}+\lambda_{2} \cdot X_{2, t-1}+\lambda_{3} \cdot X_{3, t-1}+\ldots+\lambda_{n} \cdot X_{n, t-1}+\varepsilon_{t} .
\end{aligned}
$$

We test these hypotheses to find the cointegration among variables: the null hypothesis H0: $\lambda_{0}=$ $\lambda_{1}=\lambda_{2}=\lambda_{3}=\ldots=\lambda_{n}=0$ : (no cointegration) against the alternative hypothesis H1: $\lambda_{1} \neq \lambda_{2} \neq \lambda_{3} \neq$ $\ldots \neq \lambda_{n} \neq 0$. (there exists cointegration among variables). The null hypothesis is rejected if the $\mathrm{F}$ statistic is greater than the upper bound critical value at standard significance level. If the F statistic is smaller than the lower bound critical value, $\mathrm{H} 0$ cannot be rejected. In case the F statistic lies between the 2 critical values, there is no conclusion about $\mathrm{H} 0$.

After the cointegration among variables is identified, we need to make sure that ARDL model is stable and trustworthy by conducting relevant tests: Wald test, Ramsey's RESET test using the square of the fitted values, Larange multiplier (LM) test, CUSUM (Cumulative Sum of Recursive Residuals) and CUSUMSQ (Cumulative Sum of Square of Recursive Residuals), which allows some important examination such as serial correlation, heteroscedasticity and the stability of residuals. After the ARDL model's stability and reliability are confirmed, short-run and long-run estimations can be implemented. Besides the flexibility of allowing both $\mathrm{I}(0)$ and $\mathrm{I}(1)$ in the model, ARDL approach to cointegration provides several more advantages over other methods [27, 28]. Firstly, ARDL can generate statistically significant result even with small sample size, while Johansen cointegration method requires a larger sample size to attain significance [25]. Secondly, while other cointegration techniques require the same lag orders of variables, ARDL allows various ones. Thirdly, ARDL technique estimates only one equation by OLS method rather than a set of equations like other techniques [30]. Finally, ARDL approach outputs unbiased long-run estimations, provided that some of the variables in the model are endogenous [10, 23].

Based on the benefits of ARDL model, in order to evaluate the asymmetric impacts of independent variables (i.e. exchange rate, interest rate, money supply and inflation) on VNIndex, we employ NARDL (Non-linear Autoregressive Distributed Lag) model proposed by Shin et al. [33] under the conditional error correction version displayed as follows:

$$
\begin{aligned}
& \Delta L V N I_{t}=\alpha+\sum_{i=1}^{p_{0}}\left(\beta_{0, i} \cdot \Delta L V N I_{t-i}\right)+\sum_{j=0}^{p_{1}^{+}}\left(\beta_{1, j}^{+} \cdot \Delta L E X_{t-j}^{+}\right)+\sum_{j=0}^{p_{1}^{-}}\left(\beta_{1, j}^{-} \cdot \Delta L E X_{t-j}^{-}\right)+ \\
& \sum_{k=0}^{p_{2}^{+}}\left(\beta_{2, k}^{+} \cdot \Delta L M S_{t-k}^{+}\right)+\sum_{j=0}^{p_{2}^{-}}\left(\beta_{2, k}^{-} \cdot \Delta L M S_{t-k}^{-}\right)+\sum_{l=0}^{p_{3}^{+}}\left(\beta_{3, l}^{+} \cdot \Delta L D R_{t-l}^{+}\right)+\sum_{l=0}^{p_{3}^{-}}\left(\beta_{3, l}^{-} \cdot \Delta L D R_{t-l}^{-}\right)+ \\
& \sum_{m=0}^{p_{4}^{+}}\left(\beta_{4, m}^{+} \cdot \Delta C P I_{t-m}^{+}\right)+\sum_{m=0}^{p_{4}^{-}}\left(\beta_{4, m}^{-} \cdot \Delta C P I_{t-m}^{-}\right)+\lambda_{0} \cdot L V N I_{t-1}+\lambda_{1}^{+} \cdot L E X_{t-1}^{+}+\lambda_{1}^{-} \cdot L E X_{t-1}^{-}+\lambda_{2}^{+} \cdot \\
& L M S_{t-1}^{+}+\lambda_{2}^{-} \cdot L M S_{t-1}^{-}+\lambda_{3}^{+} \cdot L D R_{t-1}^{+}+\lambda_{3}^{-} \cdot L D R_{t-1}^{-}+\lambda_{4}^{+} \cdot L C P I_{t-1}^{+}+\lambda_{4}^{-} \cdot L C P I_{t-1}^{-}+\varepsilon_{t} .
\end{aligned}
$$

In equation (11), LVNI is the natural logarithm of VNIndex; LEX is the natural logarithm of exchange rate; $L M S$ is the natural logarithm of money supply (M2); $L D R$ is the natural logarithm of deposit interest rate (\% per annum); $C P I$ is the natural logarithm of the index that represents inflation. The " + " and" $-"$ notations of the independent variables respectively denote the partial sum of positive and negative changes; specifically:

$$
L E X_{t}^{+}=\sum_{i=1}^{t} \Delta L E X_{i}^{+}=\sum_{i=1}^{t} \max \left(\Delta L E X_{i, 0}\right)
$$




$$
\begin{aligned}
& L E X_{t}^{-}=\sum_{i=1}^{t} \Delta L E X_{i}^{-}=\sum_{i=1}^{t} \min \left(\Delta L E X_{i, 0}\right) \\
& L M S_{t}^{+}=\sum_{i=1}^{t} \Delta L M S_{i}^{+}=\sum_{i=1}^{t} \max \left(\Delta L M S_{i, 0}\right) \\
& L M S_{t}^{-}=\sum_{i=1}^{t} \Delta L M S_{i}^{-}=\sum_{i=1}^{t} \min \left(\Delta L M S_{i, 0}\right) \\
& L D R_{t}^{+}=\sum_{i=1}^{t} \Delta L D R_{i}^{+}=\sum_{i=1}^{t} \max \left(\Delta L D R_{i, 0}\right) \\
& L D R_{t}^{-}=\sum_{i=1}^{t} \Delta L D R_{i}^{-}=\sum_{i=1}^{t} \min \left(\Delta L D R_{i, 0}\right) \\
& L C P I_{t}^{+}=\sum_{i=1}^{t} \Delta L C P I_{i}^{+}=\sum_{i=1}^{t} \max \left(\Delta L C P I_{i, 0}\right) \\
& L C P I_{t}^{-}=\sum_{i=1}^{t} \Delta L C P I_{i}^{-}=\sum_{i=1}^{t} \min \left(\Delta L C P I_{i, 0}\right)
\end{aligned}
$$

Similar to the linear ARDL method, Shin et al. [33] introduces the bound test for identifying asymmetrical cointegration in the long-run. The null hypothesis states that the effect is symmetrical in the long-run (H0: $\left.\lambda_{0}=\lambda_{1}^{+}=\lambda_{1}^{-}=\lambda_{2}^{+}=\lambda_{2}^{-}=\lambda_{3}^{+}=\lambda_{3}^{-}=\lambda_{4}^{+}=\lambda_{4}^{-}=0\right)-$ On the contrary, the alternative hypothesis states that the effect is asymmetrical in the long-run (H1: $\lambda_{0} \neq \lambda_{1}^{+} \neq \lambda_{1}^{-} \neq \lambda_{2}^{+} \neq$ $\lambda_{2}^{-} \neq \lambda_{3}^{+} \neq \lambda_{3}^{-} \neq \lambda_{4}^{+} \neq \lambda_{4}^{-} \neq 0$ ). The $\mathrm{F}$ statistic and critical values are also used to give conclusion about $\mathrm{H} 0$. If $\mathrm{H} 0$ is rejected, there exists asymmetrical effect.

When cointegration is identified, the calculation procedure of NARDL is similar to that of the traditional ARDL. Also, Wald test, functional form, Larange multiplier (LM) test, CUSUM (Cumulative Sum of Recursive Residuals) and CUSUMSQ (Cumulative Sum of Square of Recursive Residuals) are necessary to ensure the trustworthiness and stability of NARDL model.

\section{Estimation Sample and Data}

We use monthly data from April, 2001 to October, 2017. The variables are described in Table 1.

Table 1. Descriptive statistics.

\begin{tabular}{|l|l|l|l|l|l|}
\hline Variable & Obs & Mean & Std. Dev. & Max & Min \\
\hline LVNI & 199 & 6.03841 & 0.494204 & 7.036755 & 4.914198 \\
LEX & 199 & 9.803174 & 0.146436 & 10.01971 & 9.553859 \\
LMS & 199 & 14.20515 & 1.099867 & 15.83021 & 12.28905 \\
LDR & 199 & 1.987935 & 0.333566 & 2.842581 & 1.543298 \\
LCPI & 199 & 2.368312 & 0.934708 & 4.036674 & -1.04759 \\
\hline
\end{tabular}

Source: Authors' collection and calculation 
LVNI is the natural logarithm of VNIndex which is retrieved from Ho Chi Minh City Stock Exchange (http://www.hsx.vn). LEX is the natural logarithm of exchange rate. LMS is the natural logarithm of money supply (M2). $L D R$ is the natural logarithm of deposit interest rate (\% per annum). LCPI is the natural logarithm of the index that represents inflation. In this study, we apply the inverse hyperbolic sine transformation formula mentioned in Burbidge et al. [4] to deal with negative value of inflation (see also e.g., [1, 6]). The macroeconomic data is collected from IMF's International Financial Statistics.

\section{The Empirical Results}

Whereas unit root test is not compulsory for ARDL approach, we utilize Augmented Dickey-Fuller (ADF) test and Phillips-Perron (PP) test to confirm that the variables are not integrated at second level difference so that F-test is trustworthy [20, 28].

The result of ADF test and PP test (displayed in Table 2) denotes that $L C P I$ is stationary at level while LVNI, LEX, LMS, and LDR are stationary at first level difference, which means that the variables are not integrated at second level difference. Thus, the F statistic shown in Table 3 is valid for cointegration test among variables.

Table 2. ADF and PP tests results for non-stationarity of variables.

\begin{tabular}{|l|l|l|l|l|}
\hline \multirow{2}{*}{ Variable } & \multicolumn{2}{|l|}{ ADF test statistic } & \multicolumn{2}{l|}{ PP test statistic } \\
\cline { 2 - 5 } & Intercept & Intercept and trend & Intercept & Intercept and trend \\
\hline$L V V I_{t}$ & -1.686 & -2.960 & -1.420 & -2.324 \\
LEN $X_{t}$ & $-10.107^{* * *}$ & $-10.113^{* * *}$ & $-10.107^{* * *}$ & $-10.157^{* * *}$ \\
$\Delta L E X_{t}$ & -0.391 & -1.449 & -0.406 & -1.5108 \\
$L M S_{t}$ & $-15.770^{* * *}$ & $-15.730^{* * *}$ & $-15.792^{* * *}$ & $-15.751^{* * *}$ \\
$\Delta L M S_{t}$ & -2.298 & 0.396 & -1.957 & 0.047 \\
$L D R_{t}$ & $-11.914^{* * *}$ & $-12.207^{* * *}$ & $-12.138^{* * *}$ & $-12.305^{* * *}$ \\
$\Delta L D R_{t}$ & -2.336 & -2.478 & -1.833 & -1.907 \\
$L C P I_{t}$ & $-8.359^{* * * *}$ & $-8.452^{* * *}$ & $-8.5108^{* * *}$ & $-8.598^{* * *}$ \\
\hline
\end{tabular}

Note: ${ }^{* * *},{ }^{* *}$ and ${ }^{*}$ are respectively the $1 \%, 5 \%$ and $10 \%$ significance level.

Source: Authors' collection and calculation 
Table 3. The result of bound tests for cointegration test

\begin{tabular}{|l|l|l|l|l|l|l|l|l|}
\hline \multirow{2}{*}{ F statistic } & \multicolumn{2}{|c|}{$90 \%$} & \multicolumn{2}{c|}{$95 \%$} & \multicolumn{2}{c|}{$97.5 \%$} & \multicolumn{2}{c|}{$99 \%$} \\
\cline { 2 - 9 } & $\mathrm{I}(0)$ & $\mathrm{I}(1)$ & $\mathrm{I}(0)$ & $\mathrm{I}(1)$ & $\mathrm{I}(0)$ & $\mathrm{I}(1)$ & $\mathrm{I}(0)$ & $\mathrm{I}(1)$ \\
\hline $4.397^{* *}$ & 2.711 & 3.800 & 3.219 & 4.378 & 3.727 & 4.898 & 4.385 & 5.615 \\
\hline
\end{tabular}

Note: The asterisks ${ }^{* * *},{ }^{* *}$ and ${ }^{*}$ are respectively the $1 \%, 5 \%$ and $10 \%$ significance level.

Source: Authors' collection and calculation

From Table 3, the F statistic (4.397) is larger than the upper bound critical value (4.378) at 5\% significance level, which indicates the occurrence of cointegration (or long-run relationship) between VNIndex and its determinants. Next, according to Schwartz Bayesian Criterion (SBC), the maximum lag order equals 6 to save the degree of freedom. Also, based on SBC, we can apply NARDL $(2,0,0$, $0,0,1,0,0,0)$ demonstrated in Table 4 .

Table 4. Results of asymmetric ARDL model estimation.

\begin{tabular}{|c|c|c|}
\hline \multicolumn{3}{|c|}{ Dependent variable: $L V N I$} \\
\hline Variahle & Coefficient & t-statistic \\
\hline$I . V N I_{t-1}$ & $1.1102^{* * *}$ & 15.5749 \\
\hline$L V N I_{t-2}$ & $-0.30426^{* * *}$ & -4.7124 \\
\hline$L E X_{+}^{+}$ & 0.12941 & 0.45883 \\
\hline$L E X_{+}^{-}$ & -1.4460 & -1.3281 \\
\hline$L M S_{+}^{+}$ & $0.30997^{* * *}$ & 4.2145 \\
\hline$L M S_{+}^{-}$ & $2.3502^{* * *}$ & 2.5959 \\
\hline$L D R_{t}^{+}$ & $-0.58472^{* * *}$ & -3.2742 \\
\hline$L D R_{t-1}^{+}$ & $0.45951^{* *}$ & 2.4435 \\
\hline$L D R_{+}^{-}$ & $0.13895^{* * *}$ & 2.6369 \\
\hline$L C P I_{+}^{+}$ & $-0.034060^{* *}$ & -2.3244 \\
\hline$L C P I_{+}^{-}$ & $-0.030785^{* *}$ & -1.9928 \\
\hline constant & $1.0226^{* * *}$ & 4.4333 \\
\hline \multicolumn{3}{|c|}{ Adj $-R^{2}=0.97200$} \\
\hline \multicolumn{3}{|c|}{$D W-$ statistics $=1.8865$} \\
\hline \multicolumn{3}{|c|}{ SE of Regression $=0.083234$} \\
\hline \multirow[t]{4}{*}{ Diagnostic tests } & A: Serial Correlation & ChiSQ $Q(12)=0.0214[0.884]$ \\
\hline & B: Functional Form & $\operatorname{ChiSQ}(1)=1.4231[0.233]$ \\
\hline & C: Normality & $\operatorname{ChiSQ}(2)=0.109[0.947]$ \\
\hline & D: Heteroscedasticity & $\operatorname{ChiSQ}(1)=0.2514[0.616]$ \\
\hline
\end{tabular}


Note: ${ }^{* *},{ }^{* *}$ and ${ }^{*}$ are respectively the $1 \%, 5 \%$ and $10 \%$ significance level.

A: Lagrange multiplier test of residual serial correlation

B: Ramsey's RESET test using the square of the fitted values

C: Based on a test of skewness and kurtosis of residuals

D: Based on the regression of squared residuals on squared fitted values

Source: Authors' collection and calculation

Table 4 denotes that the overall goodness of fits of the estimated equations is very high (approximately 0.972 ), which means $97.2 \%$ of the fluctuation in VNIndex can be explained by exchange rate, interest rate, money supply and inflation. The diagnostic tests show no issue with our model.

Figures 1 and 2 illustrate CUSUM and CUSUMSQ tests. As cumulative sum of recursive residuals and cumulative sum of square of recursive residuals both are within the critical bounds at $5 \%$ significance level, our model is stable and trustworthy to estimate short-run and long-run coefficients.

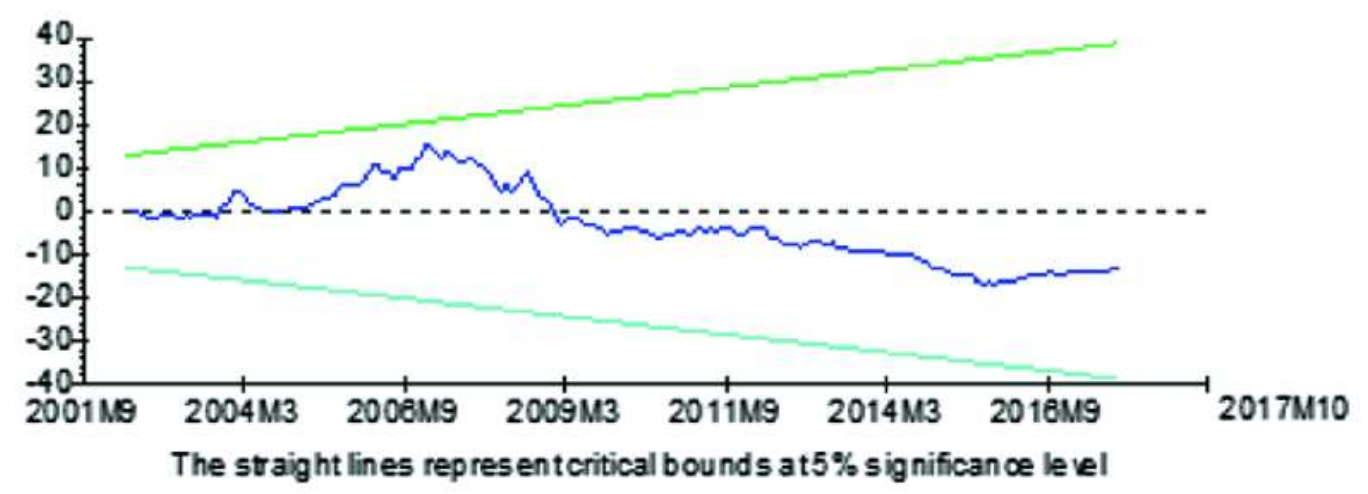

Fig. 1. Plot of cumulative sum of recursive residuals (CUSUM)

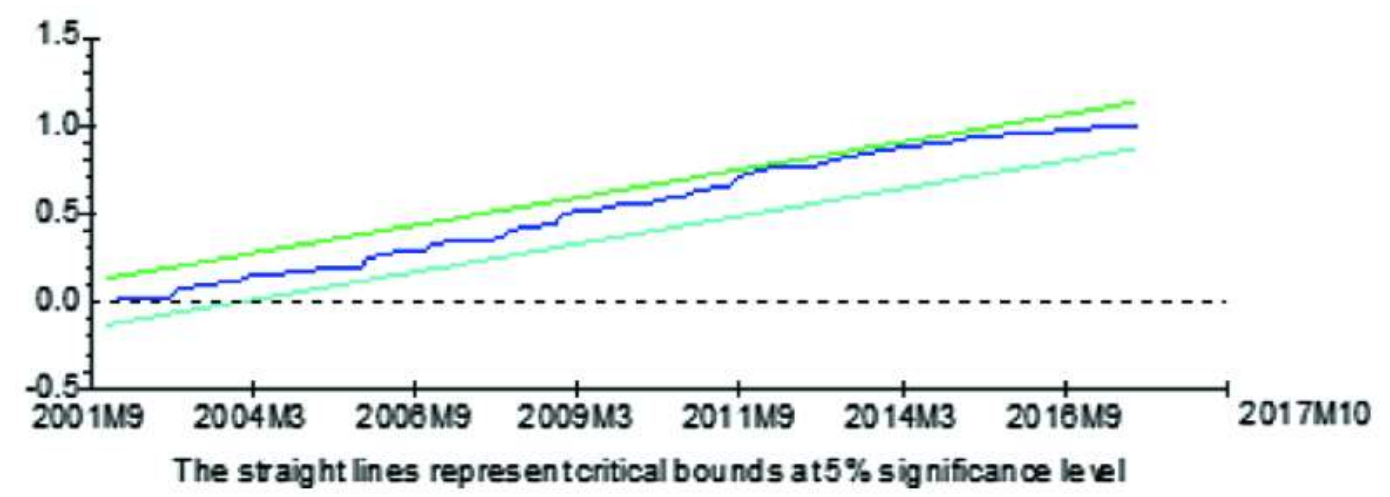

Fig. 2. Plot of cumulative sum of squares of recursive residuals (CUSUMSQ)

The estimation result of asymmetrical short-run and long-run coefficients of our NARDL model is listed in Table 5.

The error correction term $E C_{t-1}$ is negative and statistically significant at $1 \%$ level, and thus, it once again shows the evidence of cointegration among variables in our model and indicates the speed of adjustment from short-run towards long-run [28]. 
Table 5. Result of asymmetric short-run and long-run coefficients.

\begin{tabular}{|c|c|c|}
\hline \multicolumn{3}{|c|}{ Asymmetric long-run coefficients (dependent variable: $L V N I_{t}$ ) } \\
\hline Variable & Coefficient & t-statistic \\
\hline$L E X_{t}^{+}$ & 0.66680 & 0.46230 \\
\hline$L E X_{t}^{-}$ & -7.4509 & -1.2003 \\
\hline$L M S_{t}^{+}$ & $1.5972^{* * *}$ & 8.9727 \\
\hline$L M S_{t}^{-}$ & $12.1097^{* * *}$ & 2.8762 \\
\hline$L D R_{t}^{+}$ & $-0.64513^{* * *}$ & -2.7839 \\
\hline$L D R_{t}^{-}$ & $0.71594^{* * *}$ & 2.9806 \\
\hline$L C P I_{t}^{+}$ & $-0.17550^{* * *}$ & -2.5974 \\
\hline$L C P I_{t}^{-}$ & $-0.15862^{* *}$ & -1.9998 \\
\hline constant & $5.2689^{* * *}$ & 14.7685 \\
\hline \multicolumn{3}{|c|}{ Asymmetric long-run coefficients (dependent variable: $\Delta L V N I_{t}$ ) } \\
\hline Variable & Coefficient & t-statistic \\
\hline$\Delta L V N I_{t-1}$ & $0.30426^{* * *}$ & 4.7124 \\
\hline$\Delta L E X_{t}^{+}$ & 0.12941 & 0.45883 \\
\hline$\Delta L E X_{t}^{-}$ & -1.4460 & -1.3281 \\
\hline$\Delta L M S_{t}^{+}$ & $0.30997^{* * *}$ & 4.2145 \\
\hline$\Delta L M S_{t}^{-}$ & $2.3502^{* * *}$ & 2.5959 \\
\hline$\Delta L D R_{t}^{+}$ & $-0.58472^{* * *}$ & -3.2742 \\
\hline$\Delta L D R_{t}^{-}$ & $0.13895^{* * *}$ & 2.6369 \\
\hline$\Delta L C P I_{t}^{+}$ & $-0.034060^{* *}$ & -2.3244 \\
\hline$\triangle L C P I_{t}^{-}$ & $-0.030785^{* *}$ & -1.9928 \\
\hline constant & $1.0226^{* * *}$ & 4.4333 \\
\hline$E C_{t-1}$ & $-0.19408^{* * *}$ & -5.42145 \\
\hline
\end{tabular}

Note: The asterisks ${ }^{* * *},{ }^{* *}$ and ${ }^{*}$ are respectively the $1 \%, 5 \%$ and $10 \%$ significance level.

Source: Authors' collection and calculation 


\section{Conclusion}

This study analyzes the impacts of some macroeconomic factors on Vietnam's stock market. The result of Non-linear ARDL approach indicates statistically significant asymmetrical effects of money supply, interest rate and inflation on VNIndex.

Specifically, money supply increases VNIndex in both short-run and long-run, and there is considerable difference between the negative cumulative sum of changes and the positive one where the magnitude of the former is much more than that of the latter.

The positive cumulative sum of changes of interest rate worsens VNIndex, whereas the negative analogue improves VNIndex. Besides, in the short-run, the effect of the positive component is substantially higher than the negative counterpart, yet the reversal is witnessed in the long-run.

Both the positive and negative cumulative sum of changes of inflation exacerbate VNIndex. Nonetheless, the asymmetry between them is relatively weak, thus akin to the negative linear connection between inflation and VNIndex reported by existing empirical studies in Vietnam. Consequently, inflation is normally deemed as "the enemy of stock market", and it necessitates effective policies so that the macroeconomy can develop sustainably, which in turn fosters the stable growth of stock market, attracts capital from foreign and domestic investors and increases their confidence. Also, the State Bank of Vietnam needs flexible approaches to manage money supply and interest rate based on market mechanism; specifically, monetary policy should be established in accordance with the overall growth strategy for each period and continuously monitored so as to avoid instant shocks that aggravate the economy as well as stock market investors.

Finally, the findings recommend stock market investors to notice the changes in macroeconomic factors as they have considerable effects on, and can be employed as indicators of, the stock market.

\section{Notes}

Acknowledgements: This study has received funding from the European Union's Horizon 2020 research and innovation programme under the Marie Sklodowska-Curie grant agreement No 734712.

\section{References}

1. J. L. Arcand, E. Berkes and U. Panizza, “Too much finance?”, IMF Working Paper, 2012, WP/12/161.

2. J. H. Boyd, J. Hu and R. Jagannathan, "The stock markets reaction to unemployment news: Why bad news is usually good for stocks?", The Journal of Finance, 2005, Vol. 60, No. 2, pp. 649-672.

3. T. Brahmasrene and J. Komain, "Cointegration and causality between stock index and macroeconomic variables in an emerging market", Academy of Accounting and Financial Studies Journal, 2007, No. 11, pp. 17-30.

4. J. B. Burbidge, L. Magee and A. L. Robb, "Alternative Transformations to Handle Extreme Values of the Dependent Variable", Journal of the American Statistical Association, 1988, Vol. 83, No. 401, pp. 123-127.

5. J. H. Cochrane, "Production-based asset pricing and the link between stock returns and economic fluctuations", The Journal of Finance, 1991, Vol. 46, No. 1, pp. 209-237.

6. J. Creel, P. Hubert and F. Labondance, "Financial stability and economic performance”, Economic Modelling, 2015, No. 48 , pp. $25-40$.

7. D.A. Dickey and W. A. Fuller, "Distribution of the estimators for autoregressive time series with a unit root", Journal of the American Statistical Association, 1979, Vol. 74, No. 366, pp. 427-431.

8. R. F. Engle and C. W. J. Granger, "Co-Integration and Error Correction: Representation, Estimation, and Testing", Econometrica, 1987, Vol. 55, No. 2, pp. 251-276.

9. A. Gul and N. Khan, "An application of arbitrage pricing theory on KSE100 index; A study from Pakistan (20002005)", IOSR Journal of Business and Management, 2013, Vol. 7, No. 6, pp. 78-84.

10. R. Harris and R. Sollis, Applied Time Series Modelling and Forecasting, West Sussex: Wiley, 2003.

11. Y. Hsing, "Impacts of macroeconomic variables on the stock market in Bulgaria and policy implications", Journal of Economics and Business, 2011, Vol. 14, No. 2, pp. 41-53.

12. A. Humpe and P. Macmillan, "Can macroeconomic variables explain long-term stock market movements? A comparison of the US and Japan", Applied Financial Economics, 2009, Vol. 19, No. 2, pp. 111-119. 
13. M. Ibrahim and A. Musah, "An Econometric Analysis of the Impact of Macroeconomic Fundamentals on Stock Market Returns in Ghana", Research in Applied Economics, 2014, Vol. 6, No. 2, pp. 47-72.

14. F. Jareno and E. Navarro, "Stock interest rate risk and inflation shocks", European Journal of Operational Research, 2010, Vol. 201, No. 2, pp. 337-348

15. S. Johansen, "Statistical Analysis of Cointegration Vectors", Journal of Economic Dynamics and Control, 1988, Vol. 12, No. 2-3, pp. 231-254.

16. D. Kwiatkowski, P. C. B. Phillips, P. Schmidt and Y. Shin, "Testing the null hypothesis of stationarity against the alternative of a unit root: How sure are we that economic time series have a unit root?", Journal of Econometrics, 1992, Vol. 54, No. 1-3, pp. 159-178.

17. C. Mutuku and K. L. Ng'eny, "Macroeconomic Variables and the Kenyan Equity Market: A Time Series Analysis", Business and Economic Research, 2015, Vol. 5, No. 1, pp. 1-10.

18. P. K. Naik, “Does Stock Market Respond to Economic Fundamentals? Time series Analysis from Indian Data”, Journal of Applied Economics \& Business Research, 2013, Vol. 3, No. 1, pp. 34-50.

19. P. T. B. Nguyet and P. D. P. Thao, "Analyzing the impact of macroeconomic factors on Vietnam's stock market", Journal of Development $\mathcal{E}$ Integration, 2013, Vol. 8, No. 18, pp. 34-41.

20. B. Ouattara, "Modelling the long run determinants of private investment in Senegal", The School of Economics Discussion Paper Series 0413, The University of Manchester, 2004.

21. A. Peiro, "Stock prices, production and interest rates: comparison of three European countries ' with the USA", Empirical Economics, 1996, Vol. 21, No. 2, pp. 221-234.

22. A. Peiro, "Stock prices and macroeconomic factors: Some European evidence", ' International Review of Economics $\mathcal{E}$ Finance, 2016, No. 41, pp. 287-294.

23. M. H. Pesaran and B. Pesaran, Microfit 4.0 (Window Version), Oxford University Press, 1997.

24. M. H. Pesaran and Y. Shin, "An Autoregressive Distributed Lag Modeling Approach to Cointegration Analysis", In: Strom, S., Ed., Econometrics and Economic Theory: The Ragnar Frisch Centennial Symposium, Cambridge University Press, Cambridge, 1998, pp. 371-413. 